\title{
Identifying How to Support Nurse Educators Nationally to Teach Nursing Informatics
}

\author{
Michelle HONEY ${ }^{\mathrm{a}, 1}$, Emma COLLINS $^{\mathrm{b}}$ and Sally BRITNELL ${ }^{\mathrm{c}}$ \\ a School of Nursing, University of Auckland, Auckland, New Zealand \\ ${ }^{\mathrm{b}}$ School of Nursing, Otago Polytechnic, Dunedin, New Zealand \\ ${ }^{c}$ Nursing Department, School of Clinical Sciences, Auckland University of Technology, \\ Auckland, New Zealand
}

\begin{abstract}
Preparing nurses for practice and ensuring nursing informatics is included in their curricula is a challenge for many nurse educators. This study asked nurse educators from around New Zealand $(n=40)$ what they perceived as the concerns, barriers and facilitators to implementing nursing informatics within their curricula. Among the findings a key issue is the constantly evolving nature of information and communication technology in healthcare and nursing which results in the ongoing need for professional development to keep up-to-date. Outcomes from this study are recommendations which will inform our next steps in this project to support nurse educators provide the best education possible for new nurses.
\end{abstract}

Keywords. Nurse teachers, nursing education, professional development, curricula

\section{Introduction}

Keeping education relevant and up to date amongst rapidly evolving technology is an internationally recognized issue [1]. Constant advances in technology also causes issues for nursing education with ongoing changes in the educational and healthcare landscape $[2,3]$. One issue related to this is keeping the nursing informatics curricula content current, and another is ensuring nurse educator's knowledge and application of nursing informatics in practice is also current thereby enabling them to teach this subject [4-6]. This paper reports on a national project to identify the nurse educators' concerns, barriers and facilitators to implementing nursing informatics within their curricula. The site for this study was New Zealand.

\subsection{The Project}

Having nurse educators prepared to teach nursing informatics and to be able to role model nursing informatics in practice in an ever-changing health care environment is an international concern $[3,5]$. However, the way in which nursing informatics in entry to practice education is addressed in each country varies $[4,7]$.

${ }^{1}$ Corresponding Author, Dr Michelle Honey, School of Nursing, University of Auckland, Private Bag 92019, Victoria Street West, Auckland 1142, New Zealand; E-mail: m.honey@auckland.ac.nz. 
In 2016 a project commenced in New Zealand to identify the nursing guidelines needed for nurses at the end of their undergraduate nursing education programme as they entered practice as Level One, or novice Registered Nurses. These were published as "Guidelines for Nursing Informatics Competencies for Undergraduate Nurses in New Zealand" and launched in 2018 [8]. The process of developing these Guidelines is described elsewhere [9]. The next step after launching The Guidelines was to ensure their dissemination and uptake into nursing schools in NZ so nursing informatics can be better incorporated into nursing curricula. With a small grant to support this, four regional meetings were planned so that all Schools of Nursing in New Zealand had the opportunity to engage. We were interested in identifying concerns, barriers and facilitators for Schools of Nursing to implement The Guidelines with their nursing students.

\subsection{Regional Meetings}

All 17 Schools of Nursing in New Zealand were invited, through the Head of School, to participate in one of four regional meetings held in Auckland, Hamilton, Wellington and Dunedin. The meeting was a half day event offered in a workshop format. The format was:

- Introductions

- Discussion about the scope of nursing informatics

- The Guidelines and how they were developed

- Discussion of curriculum mapping

- Participants mapped their own curricula against The Guidelines using a curriculum mapping tool developed for this purpose. Participants took these curricula maps away with them to facilitate discussions within their own Schools of Nursing.

- Group activity - to identify barriers, concerns and facilitators to embedding nursing informatics.

In the final activity participants were asked to brainstorm what they saw as the concerns, barriers and facilitators to being able to embed nursing informatics within their curricula.

\section{Methods}

Each School of Nursing in NZ was invited to participate and to send up to three participants to one of four regional meetings. The optional research component of the workshop was to identify concerns, barriers and facilitators to implementation of The Guidelines with their students. Ethical approval was obtained from the University of Auckland Human Participants Ethics Committee (Reference number: 022823). Ethical approval was for permission to use their brainstormed ideas so they could be collated, shared with participants and form the basis for publications. More importantly it was hoped that the findings would inform our next steps in this project where the project team hope to gain further funding to address identified concerns or barriers or develop resources to support the implementation of The Guidelines into nursing curricula nationally. Data analysis involved collating the data from the four regional meetings, transferring these to electronic format, summarising the data supported by visualisation 
using tree diagrams and word clouds, before final analysis and interpretation by the authors singularly and then together.

\section{Results}

All the 17 Schools of Nursing in New Zealand were invited to send participants to the four regional meetings and 16 accepted (94\% participation rate) with a total of 40 individual educators attending. The headings of concerns, barriers and facilitators are used below to present the findings.

\subsection{Concerns}

The dominant concern for participants was the continual evolution of information and communication technology (ICT) and that staff and students need to "keep up" with current informatics practice and technology. Alongside this, ensuring staff motivation and a consistent knowledge base was important and recognised as being connected with ICT evolution. The cost of evolving technology was also a concern as it impacts equitable access to services and devices across academic and clinical settings. Alongside cost, was ensuring technology is fit for purpose, that support for staff and students was identified, and the current lack of support was a concern. From the nurse educator's perspective how to implement nursing informatics content in addition to an already full curriculum was seen as difficult. Lesser concerns were sustainability in relation to e-waste; security, confidentiality and the potential for unprofessional behaviour online.

\subsection{Barriers}

Many barriers were identified by the participants and while the majority were focused at a macro level, a number were local issues specific to a School of Nursing. The most common barriers mentioned included cost, policy, training, staffing and support.

The barriers that suggest that a local response was needed included liaising with key stakeholders, knowing the enrolled students and their learning environment. For example, in one location students did not have access to the local hospital ICT systems. A local effort to gain student training and access was needed. The student population at each School of Nursing varies, so understanding the socio-economic situation, access to the internet and devices is warranted. It is easy to assume most students are competent with the technology, language and systems that are used in education and practice, without assessing their capabilities. There could be potential barriers to learning that need to be addressed for students to be effective learners of nursing informatics.

Several of the identified barriers could be overcome at a national level. The most obvious barrier, which is also the most challenging, is cost. A number of ICT products that are used in healthcare are provided with training packages for hospital or organisational staff only. However, students could also benefit from training. Alternatively, access to training packages of systems that replicate those the students need to engage with in clinical practice could be provided to Schools of Nursing, but the cost of these are prohibitive. National funding to access training packages would make them considerably more accessible to students, and therefore better prepare them for practice. Nurse educators identified that lack of time was a barrier. Many participants mentioned that if they had more time, they could ensure students were engaging with 
nursing informatics. This also relates to cost in terms of staffing, workload and resources. The next most significant barrier that could be overcome at a national level was around workforce and capacity building of nurse educators.

\subsection{Facilitators}

There were many facilitators to implementing nursing informatics that were identified. These included having highly motivated staff who were engaged with this aspect of nursing education, having a health system that supported the informatics growth of nursing students, and an organisation that dedicated time and resources to nursing informatics. Participants indicated they wished for nursing informatics curriculum guidance and that this could be best provided at a national level, across all Schools of Nursing. The curriculum mapping exercise undertaken by participants from each school at the regional meetings was considered helpful as a starting point. Further support was requested in terms of how to best integrate nursing informatics to develop an overt and explicit nursing informatics curricula thread.

As indicated under barriers and concerns a key challenge is the constantly evolving nature of ICT. Furthermore, when looking at facilitators this is demonstrated in the most dominant issue being the need professional development for nurse lecturers. Having the opportunities to learn from each other was considered one way to support professional development. This was considered a cost-effective method, which also recognised the existing skills and abilities of experienced nurse lecturers. The aim that was indicated as being needed, was 'inspirational teaching of nursing informatics' and that achieving this would also increase nurse lecturer motivation in terms of teaching nursing informatics, but also enable imaginative teaching and learning strategies to develop. To further support 'inspirational teaching of nursing informatics' participants suggested that having nationally available resources would be helpful, though also indicate that these could be shared resources, rather than just having them provided.

\section{Discussion}

In terms of having students undertake clinical, stronger partnerships and collaboration with clinical partners was indicated as being needed as stronger partnerships with local clinical settings may address issues around access to the internet and clinical systems. A lack of resources and equipment was a concern and barrier. Providing devices for nurse lecturers to use can facilitating role-modelling of use of ICT as part of practice, including nursing practice as an educator. Specifically, devices such as a laptop, or tablet for easier portability in clinical settings was suggested. Additionally, a further barrier, was lack of access to devices for students. Participants acknowledged that not all students had easy access to ICT for their learning; and equity in access to technology is a known problem [10]. These issues are not unique. For example, the importance of clinical and academic partnerships is recognised [11]; as is the influence of nurse educators' positive attitude and their ability to role model use of technology [12]. Providing nationally available resources is not novel, and Canada has led the way through assessing and addressing the needs of their nurse educators [13]. 


\subsection{Recommendations and Areas for Future Research}

Recommendations that are considered achievable in the short term include: Assess the current knowledge and skills of students; explore how to support collaboration among nurse educators for professional development; develop nursing informatics content and teaching resources that can be available nationally; provide nursing informatics curricula guidance. Longer term recommendations include: Each School of Nursing to develop stronger partnerships with their clinical partners to obtain access to the internet and clinical systems for students on clinical placements; devices, such as smart phones and tablets be provided to nurse lecturers as part of the equipment needed to do their job; explore ways students can be supported to have access to a device for their learning (for example, early notification of devices needed and recommended specifications, bulk buying, subsidies, loan devices); develop a national survey of nursing students around their ICT needs and current capabilities, to gain a national perspective; lobby central government for funding for ICT in nursing - funding for education providers; working with product providers for more cost-effective solutions; and building capacity around ICT in nursing.

\section{Conclusion}

Asking New Zealand nurse educators about their concerns, barriers and facilitators to implementing nursing informatics within their curricula identified a number of issues, and outcomes from this study are less definitive, but rather provide recommendations and areas for further research.

\section{References}

[1] Johnson L, Adams Becker S, Cummins M, Estrada V, Freeman A, Hall C. NMC Horizon Report: 2016 higher education edition. The New Media Consortium, Austin, TX, 2016.

[2] Hübner U, Shaw T, Thye J et al. Technology Informatics Guiding Education Reform - TIGER: An international recommendation framework of core competencies in health informatics for nurses. Methods of Information in Medicine 57, (2018), e30-e42.

[3] Murphy J, Goossen W, Weber P, eds. Forecasting informatics competencies for nurses in the future of connected health: Proceedings of the Nursing Informatics Post Conference 2016. Amsterdam, The Netherlands: IOS Press; 2017.

[4] Egbert N, Thye J, Hackl WO, Müller-Staub M, Ammenwerth E, Hübner U. Competencies for nursing in a digital world: Methodology, results, and use of the DACH recommendations for nursing informatics core competency areas in Austria, Germany, and Switzerland. Informatics for Health and Social Care (2018).

[5] Kinnunen U, Rajalahti E, Cummings E, Borycki EM. Curricula challenges and informatics competencies for nurse educators. Studies in Health Technology \& Informatics 232, (2017), 41-48.

[6] Mather CA, Cummings EA. Issues for deployment of mobile learning by nurses in Australian healthcare settings. Studies in Health Technology and Informatics 225, (2016), 277-281.

[7] Honey M, Skiba DJ, Procter P, Foster J, Kouri P, Nagle LM. Nursing informatics competencies for entry to practice: The perspective of six countries. In: Murphy J, Goossen W, Weber P, eds. Forecasting informatics competencies for nurses in the future of connected health, IOS Press, Amsterdam, The Netherlands, 2017, 51-61.

[8] Honey M, Collins E, Britnell S. Guidelines: Informatics for nurses entering practice. Auckland, New Zealand, 2018.

[9] Honey M, Collins E, Britnell S. Education into policy: Embedding health Informatics to prepare future nurses - a New Zealand case study. Journal of Medical Internet Research - Nursing 3, (2020), e16186. 
[10] Honey M. Undergraduate student nurses' use of information and communication technology in their education. Studies in Health Technology and Informatics 250, (2018), 37-40.

[11] Bvumbwe T. Enhancing nursing education via academic-clinical partnership: An integrative review. International Journal of Nursing Sciences 3, (2016), 314-322.

[12] Neville V, Lam M, Gordon CJ. The impact of eLearning on health professional educators' attitudes to information and communication technology. Journal of Multidisciplinary Healthcare 8, (2015), 75-81.

[13] Nagle L, Clarke H. Assessing the informatics education needs in Canadian schools of nursing. 11th World Congress on Medical Informatics; 7-11 September, 2004; San Francisco, California, USA. 